\title{
Effects of NSAIDs on pre-osteoblast viability and osteogenic differentiation
}

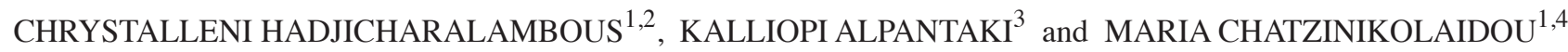

\author{
Departments of ${ }^{1}$ Materials Science and Technology, and ${ }^{2}$ Chemistry, University of Crete, Heraklion 70013; \\ ${ }^{3}$ Department of Orthopedics and Trauma, Venizeleion General Hospital of Heraklion, Heraklion 71409; ${ }^{4}$ Institute of \\ Electronic Structure and Laser (IESL), Foundation for Research and Technology Hellas (FORTH), Heraklion 70013, Greece
}

Received July 11, 2020; Accepted October 28, 2020

DOI: $10.3892 /$ etm.2021.10172

\begin{abstract}
Non-steroidal anti-inflammatory drugs (NSAIDs) are widely used in the treatment of a variety of musculoskeletal conditions, injuries and after surgery for postoperative pain management. Their use has been associated with impaired bone healing, possibly due to a multifactorial function, which may include inhibition of osteoblast recruitment and differentiation. However, up to date, there is no consensus regarding the impact of NSAIDs on bone-healing. The aim of the current study was to investigate the effects of five NSAIDs on the cellular functions of mouse MC3T3-E1 pre-osteoblasts. Cells were treated with the non-selective COX inhibitors lornoxicam and diclofenac, the COX-2 selective inhibitors parecoxib, meloxicam and paracetamol, as well as steroidal prednisolone at different doses and exposure times. The PrestoBlue $^{\mathrm{TM}}$ technique was used to measure cell viability, an enzymatic assay was employed for alkaline phosphatase (ALP) activity and alizarin red S mineral staining was used to determine osteogenic differentiation. All drugs had a negative impact on pre-osteoblast cell growth, with the exception of paracetamol. Lornoxicam, diclofenac and meloxicam reduced ALP activity, while the other NSAIDs had no effect and prednisolone strongly increased ALP activity. In contrast, calcium deposits were either unaffected or increased by NSAID treatments but were significantly decreased by prednisolone. These results provide evidence that NSAIDs may adversely affect the viability of mouse pre-osteoblast cells but their actions on the osteogenic differentiation are drug-specific. The direct
\end{abstract}

Correspondence to: Professor Maria Chatzinikolaidou, Department of Materials Science and Technology, University of Crete, Voutes University Campus, Heraklion 70013, Greece E-mail:mchatzin@materials.uoc.gr

Dr Chrystalleni Hadjicharalambous, Department of Chemistry, University of Crete, Voutes University Campus, Vasilika Vouton, Heraklion 70013, Greece

E-mail: chad@uoc.gr

Key words: non-steroidal anti-inflammatory drugs, prednisolone, MC3T3-E1, cell viability, osteogenic differentiation comparison of the effects of different NSAIDs and prednisolone on pre-osteoblasts may serve to place some NSAIDs in a preferential position for analgesic and anti-inflammatory therapy during bone repair.

\section{Introduction}

Bone healing is a complex and long process which involves the coordinated action of several cell types and a complex cascade of mechanisms and signaling pathways $(1,2)$. It can be affected by various factors, such as the degree of the fracture gap and comminution, soft tissue damage, age or nutrition as well as the administration of several pharmacological agents including steroids and antibiotics (3). Glucocorticoids are used at extremely high doses for the treatment of acute situations such as spinal cord injury or acute exacerbations of life-threatening immune disorders $(1,4)$. These drugs are potent anti-inflammatory and immunosuppressive agents that inhibit the expression of pro-inflammatory cytokines, adhesion molecules, cyclooxygenases (COX) and the production of prostaglandins (PGs) $(4,5)$. Glucocorticoids also act directly on bone cells and promote apoptosis of osteoblasts and osteocytes leading to reduced bone formation and strength (6) or steroid-induced osteoporosis after long treatment (7).

Non-steroidal anti-inflammatory drugs (NSAIDs) are also widely used in the treatment of pain, including bone fracture pain and orthopedic post-operative pain. Due to their analgesic potency, anti-inflammatory properties and restricted side effects as compared to opioids, there has been a tremendous expansion in their use worldwide $(3,8)$. NSAIDs exert anti-inflammatory effects by inhibiting the synthesis of COX enzymes that catalyze the production of PGs. PGs are lipid mediators playing an important role in bone repair and were reported to regulate inflammation, increase osteoblast proliferation and differentiation and enhance osteoclast activity and bone resorption (9). Even though the exact mechanism of action of PGs on bone cells is not clear, inhibition of PG production retards bone formation, whereas local administration of exogenous PGs can stimulate new bone formation on injured bone (3). The effect of NSAIDs on osteoblast growth has been attributed to the inhibition of PG synthesis. However, the exact mechanism is still under debate. Some NSAIDs (e.g., celecoxib, diclofenac, piroxicam and indomethacin) suppress proliferation of osteoblasts by cell cycle arrest in phase G0/G1, 
which may then suppress tissue formation and regeneration in bone remodeling $(10,11)$. In addition, changes in the expression of antigenic molecules such as CD80, CD86, and HLA-DR following treatment with NSAIDs have been reported in the MG-63 osteoblast-like cells $(12,13)$, though not in osteoblasts as reported in another publication investigating celecoxib (14). NSAIDs have been reported to affect osteoblast differentiation by altering alkaline phosphatase activity, type I collagen and the calcium mineralization, but there is no consensus in the scientific publications that leads to a general mode of action for the different NSAIDs (11). The use of NSAIDs in the clinical setting of orthopedic surgery has long been a topic of controversy (15-17). Reports from animal studies and in vitro experiments have shown that NSAIDs delayed fracture healing, caused non-union, and decreased the mineral content and matrix of the callus (18-21), whereas others studies failed to prove any inhibitory effect $(14,22,23)$.

NSAIDs exhibit differences in COX isoenzyme inhibition and are classified as 'conventional or non-selective' acting as both COX-1 and COX-2 inhibitors, or 'coxibs' acting only as COX-2 inhibitors (24). A disputable issue is the superiority of coxibs over non-selective COX inhibitors regarding bone metabolism and fracture repair (25). While some authors claimed that selective COX-2 inhibitors delayed fracture healing less than non-selective COX inhibitors (19), others point out that NSAID types compromise fracture healing and should therefore be used with caution in the clinics (26). The controversy among different studies, potentially deriving from the diversity of the experimental studies, denotes that the effects of NSAIDs on bone remain unclear. Hence, their use in fracture patients has been suggested to be cautious $(9,27)$ and further evidence of potential effects on bone cells and their precursors is imperative $(8,28)$.

Here we investigated the effects of five different COX-inhibitor NSAIDs, on the viability and osteogenic differentiation of pre-osteoblasts using the MC3T3-E1 mouse calvarial cell line. MC3T3-E1 cells were treated with the selective COX-2 inhibitors parecoxib and meloxicam, the non-selective NSAIDs lornoxicam and diclofenac, and paracetamol, a non-typical NSAID with selectivity over COX-2 (29). The widely used steroidal drug, prednisolone, was used as a means of comparison (4). Cell viability was measured based on the redox potential of living cells, with the PrestoBlue ${ }^{\mathrm{TM}}$ assay. The osteogenic differentiation was assessed with the alkaline phosphatase (ALP) activity assay and quantification of calcium deposits by means of alizarin Red S (ARS) staining.

\section{Materials and methods}

Materials and NSAIDs. Minimum essential Eagle's medium ( $\alpha$-MEM), ascorbic acid, $\beta$-glycerophosphate, penicillin/ streptomycin, fetal bovine serum (FBS), trypsin/EDTA, ARS, cetylpyridinium chloride (CPC) and p-nitrophenyl phosphate were purchased from Sigma-Aldrich; Merck KGaA. PrestoBlue $^{\mathrm{TM}}$ reagent was purchased from Invitrogen; Thermo Fisher Scientific, Inc. Lornoxicam and prednisolone were purchased from Nycomed; parecoxib from Pfizer; meloxicam from Boehringer-Ingelheim; diclofenac sodium from Novartis; and paracetamol from Uni-Pharma.
Cell culture and NSAID concentrations. The MC3T3-E1 pre-osteoblasts are a non-transformed cell line derived from newborn mouse calvaria which can differentiate to osteoblasts (30). MC3T3-E1 cells were obtained from DSMZ GmbH (DSMZ no. ACC 210). Cells were grown in $\alpha$-MEM medium supplemented with $10 \%$ fetal bovine serum (FBS) and $1 \%$ penicillin/streptomycin and subcultured once a week using trypsin/EDTA. Cultures were maintained at $37^{\circ} \mathrm{C}$ in a humidified atmosphere of $5 \% \mathrm{CO}_{2}$ in air. Cells between passages 6 and 15 were used for all the experiments.

Concentrations of NSAIDs in cell studies usually range between 1-100 $\mu \mathrm{M}\left(10^{-4}-10^{-6} \mathrm{M}\right)$, but higher or lower doses have also been reported. In this study, the concentrations were selected based on previous in vitro studies $(9,22)$, and are consistent with the most therapeutically relevant concentrations of NSAIDs $\left(10^{-5} \mathrm{M}\right.$ for non-selective NSAIDs and $10^{-6} \mathrm{M}$ for COX-2 inhibitors according to literature $(10,13)$.

Cell viability measurement. Cell viability was assessed using the PrestoBlue ${ }^{\mathrm{TM}}$ assay (Invitrogen; Thermo Fisher Scientific, Inc.). The assay is based on the cellular reduction of a resazurin-based, non-toxic metabolic indicator to a red product, which can be detected using absorbance measurements and provides a measure of cell viability. MC3T3-E1 pre-osteoblasts were seeded in 96-well plates $(5,000$ cells/well) in culture medium ( $\alpha$-MEM containing 10\% FBS) and cellular adhesion was allowed to take place without the influence of drugs. After $24 \mathrm{~h}$, culture media were replaced with drug-containing media or drug-free media (control samples) and changed every 2-3 days. Cells were treated with drugs for a total of 15 days and cell growth was monitored at 5,10 and 15 days. At each time point, Presto Blue reagent was directly added to the wells (1:10) and incubated at $37^{\circ} \mathrm{C}$ for $30 \mathrm{~min}$. Absorbance was measured using a spectrophotometer (SpectraMax M2, Molecular Devices Inc.) at 570 and $600 \mathrm{~nm}$. Culture medium was used as blank and results were expressed as \% cell viability of control (non-treated) cultures (100\%). The same cell cultures were used for sequential cell viability measurements at different time points. After each measurement supernatants were replaced with fresh culture medium with or without NSAIDs and the plates were returned to the incubator for further incubation.

Measurement of ALP activity. Measurement of increased ALP expression eitherenzymatically, histochemically or at the mRNA level is considered as an early marker and reliable indication of the osteoblastic phenotype as well as a good predictor of tissue mineralization (31). MC3T3-E1 cells were plated in 96-well plates at a density of $5 \times 10^{4}$ cells/well. On day 1 , culture medium was replaced by osteogenic medium (culture medium supplemented with $10 \mathrm{mM}$ sodium glycerophosphate and $50 \mu \mathrm{g} / \mathrm{ml}$ ascorbic acid) and cells were treated with drugs $\left(10^{-6} \mathrm{M}\right)$ for 4 or 7 days. ALP activity was assayed using an enzymatic activity assay during the first week of differentiation. Briefly, cells were rinsed with phosphate buffered saline (PBS, $\mathrm{pH}$ 7.4), lysed with $100 \mu \mathrm{l}$ lysis buffer $(0.1 \%$ Triton X-100, $50 \mathrm{mM}$ Tris-HCl, $50 \mathrm{mM}$ phenylmethylsulfonyl fluoride (PMSF), $\mathrm{pH} 10$ ) and frozen at $-60^{\circ} \mathrm{C}$. After thawing, $100 \mu \mathrm{l}$ of freshly prepared assay buffer [ $2 \mathrm{mg} / \mathrm{ml}$ p-nitrophenyl-phosphate (pNPP) substrate in $50 \mathrm{mM}$ Tris- $\mathrm{HCl}, \mathrm{pH} 10$ and $2 \mathrm{mM} \mathrm{MgCl}$ ], was added to each 
A

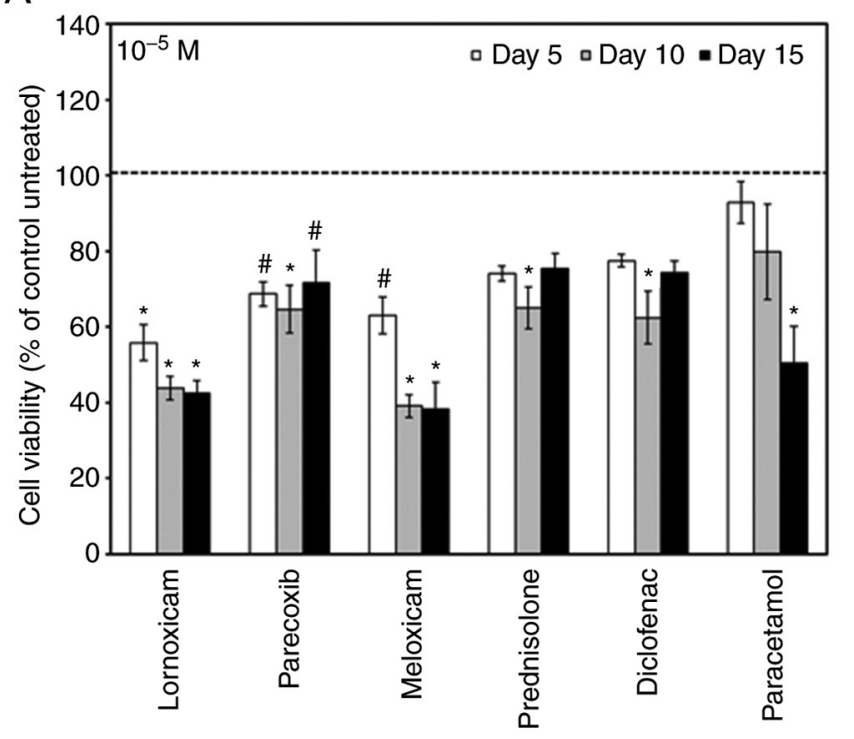

B

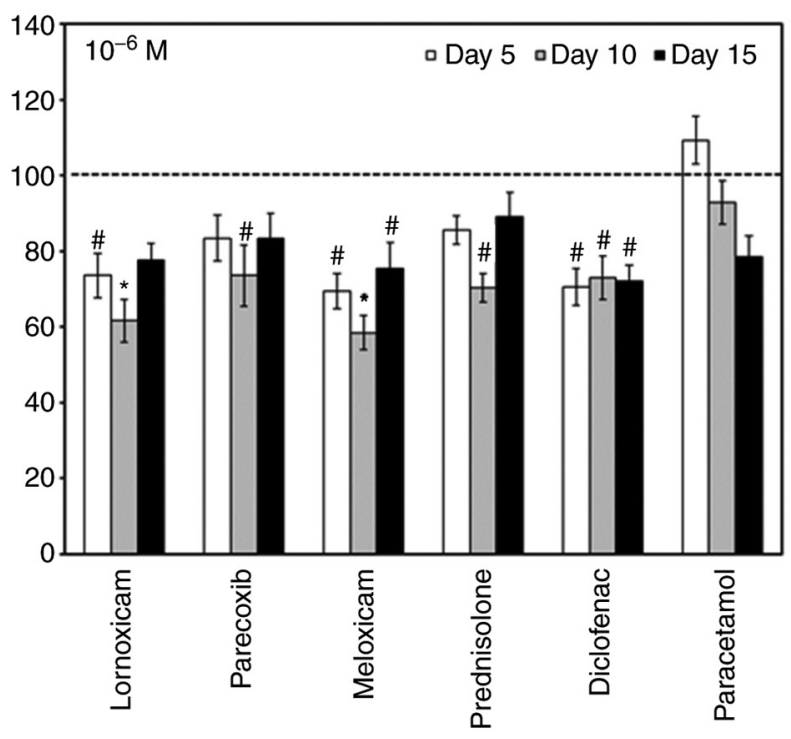

Figure 1. Anti-inflammatory drug effects on the cell viability of MC3T3-E1 growing cultures after 5, 10 and 15 days of treatment at concentrations of (A) $10^{-5}$ and (B) $10^{-6} \mathrm{M}$. At each time point data are expressed as \% cell viability based on control cultures (100\%, shown as a dotted line) without drug treatment. Each bar represents the mean \pm SEM of triplicate samples from three independent experiments $(\mathrm{n}=9)$. ${ }^{*} \mathrm{P}<0.01 \mathrm{vs}$. control; ${ }^{\#} \mathrm{P}<0.05 \mathrm{vs}$. control.

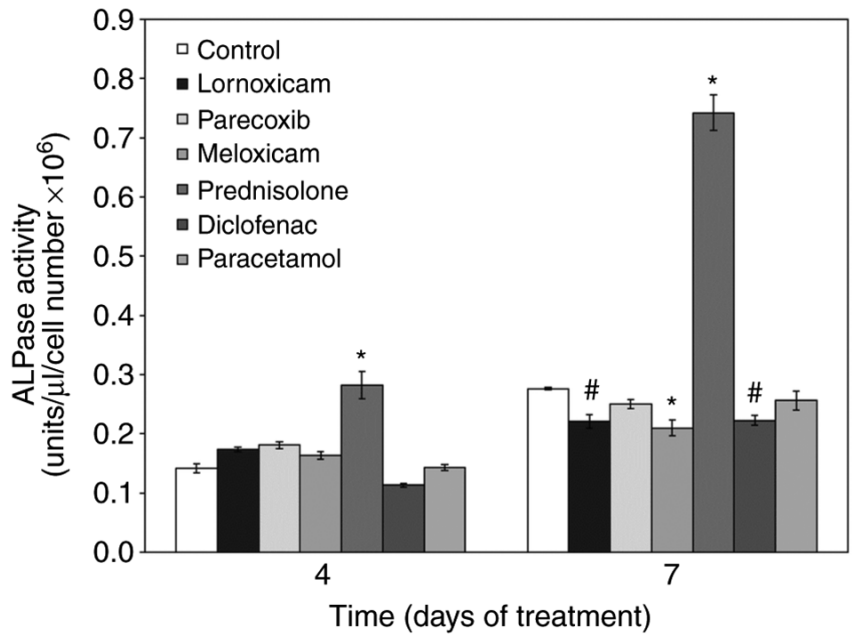

Figure 2. The effect of NSAIDs on ALP activity of differentiating MC3T3-E1 cells. Cells were grown in osteogenic medium for 21 days, in the presence of NSAIDs $\left(10^{-6} \mathrm{M}\right)$ or prednisolone $\left(10^{-6} \mathrm{M}\right)$ or in the absence of drugs (control). ALP activity is shown as enzyme units normalized to cell number Each bar represents the mean \pm SEM of triplicate samples from three independent experiments $(\mathrm{n}=9)$. ${ }^{*} \mathrm{P}<0.01$ vs. control; ${ }^{*} \mathrm{P}<0.05$ vs. control. NSAIDs, non-steroidal anti-inflammatory drugs; ALP, alkaline phosphatase.

well and the plate was incubated at $37^{\circ} \mathrm{C}$ for $30 \mathrm{~min}$. The reaction was stopped with the addition of $50 \mu \mathrm{l} 1 \mathrm{~N} \mathrm{NaOH}$. The optical density (OD) of p-nitrophenol (pNP) at $405 \mathrm{~nm}$ was measured and was correlated to equivalent amounts of pNP generated, using a calibration curve constructed of known concentrations of pNP. ALP activity was calculated using the equation [units $/ \mu \mathrm{l}=(\mathrm{nmol} p$-nitrophenol/hour $) \mathrm{x}$ dilution factor] and expressed as U/ $\mu 1$. ALP activity was normalized to cell number. For this purpose, the cell number in each well was determined with the PrestoBlue ${ }^{\mathrm{TM}}$ viability assay immediately prior to the ALP activity assay, using a calibration curve of absorbance units vs. known numbers of cells (32).
ARS staining of calcium deposits. Calcium-rich deposits representing the final stage of mineralization were assessed in cultures undergoing differentiation for 3 weeks (33). The deposits were visualized by ARS staining of cell monolayers and quantified by dye extraction (34). Initially, MC3T3-E1 cells were plated in 24-well plates at a density of $10^{5} /$ well. On day 1 , the culture medium was replaced by osteogenic medium (as described in section 2.3) and cells were treated with NSAIDs $\left(10^{-6} \mathrm{M}\right)$ or prednisolone $\left(10^{-6} \mathrm{M}\right)$ for 21 days. Cells were washed with PBS and fixed with $300 \mu 14 \%$ (v/v) paraformaldehyde (Sigma-Aldrich) for $20 \mathrm{~min}$ at room temperature. Then, they were washed three times with excess $\mathrm{dH}_{2} \mathrm{O}$ prior to staining with $300 \mu \mathrm{l} /$ well of $2 \%$ (w/v) ARS (pH 4.1) for $30 \mathrm{~min}$. Excess dye was aspirated and the cells

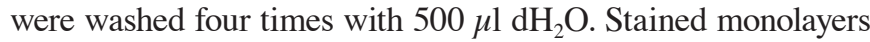
were visualized by optical microscopy. For staining quantification, $300 \mu 110 \%$ (w/v) cetylpyridinium chloride (CPC) in $10 \mathrm{mM}$ sodium phosphate ( $\mathrm{pH}$ 7.0) was added to the wells for $1 \mathrm{~h}$ under mild shaking. Aliquots $(200 \mu \mathrm{l})$ of the extract were transferred to a 96 -well plate and read in duplicates at $550 \mathrm{~nm}$. Data were expressed as units of alizarin released ( 1 unit is equivalent to 1 absorbance unit at $550 \mathrm{~nm}$ ).

Statistical analysis. Statistical analysis was performed with ANOVA (GraphPad Prism 8.0.2 software; GraphPad Software, Inc.) followed by Bonferroni's post-hoc test for multiple comparisons. One-way ANOVA with Bonferroni's post-hoc test was used with ARS experimental data, whereas two-way ANOVA with Bonferroni's post-hoc test was applied for analysis of the alkaline phosphatase activity and cell viability data. $\mathrm{P}<0.05$ was considered to indicate a statistically significant difference. Results are expressed as mean values \pm standard error to the mean (SEM).

\section{Results}

Effects of anti-inflammatory drugs on the cell viability. First, we asked whether NSAIDs affect the cell growth of 


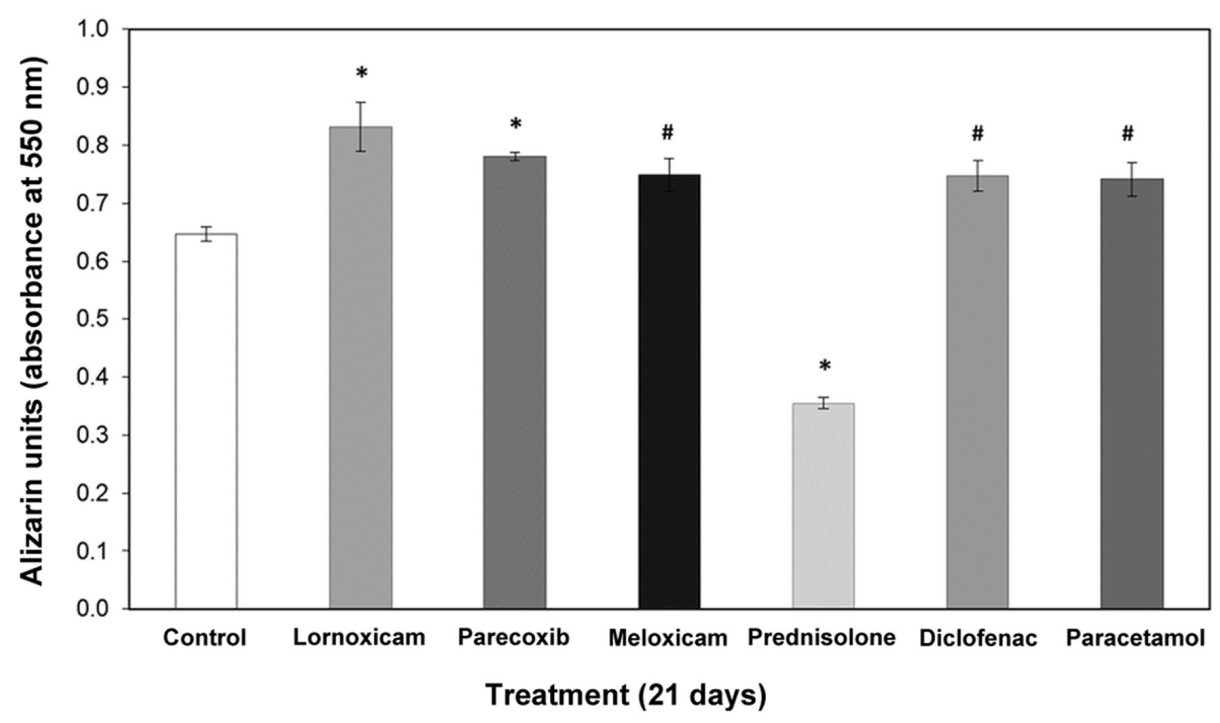

Figure 3. NSAID effects on calcium deposition in differentiating MC3T3-E1 cells. Cells were grown in osteogenic medium for 21 days, in the presence of NSAIDs $\left(10^{-6} \mathrm{M}\right)$ or prednisolone $\left(10^{-6} \mathrm{M}\right)$ or in the absence of drugs (control). Each bar represents the mean \pm SEM of triplicate samples from two independent experiments ( $\mathrm{n}=6)$. ${ }^{*} \mathrm{P}<0.01$ vs. control; ${ }^{*} \mathrm{P}<0.05$ vs. control. NSAIDs, non-steroidal anti-inflammatory drugs.

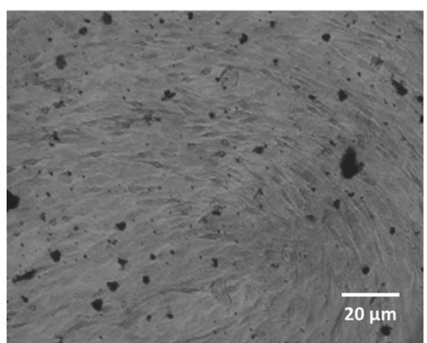

Control

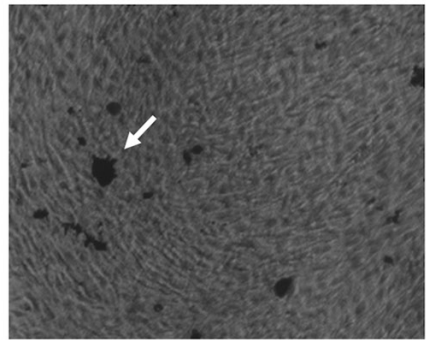

Lornoxicam

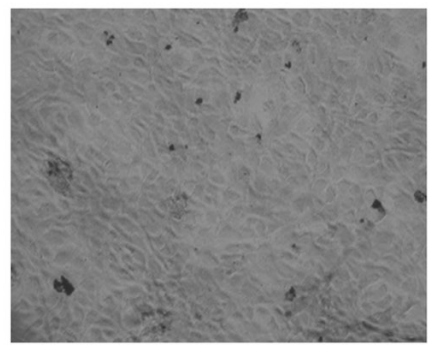

Prednisolone

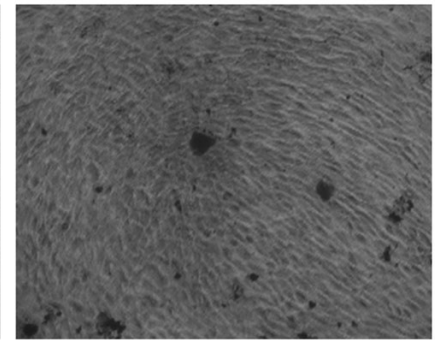

Parecoxib

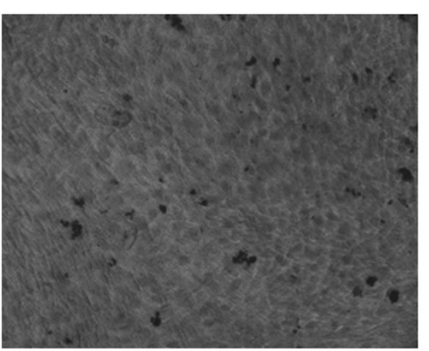

Diclofenac

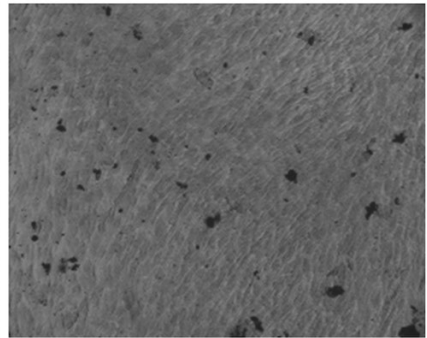

Meloxicam

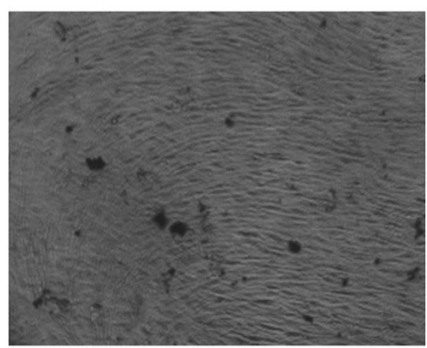

Paracetamol

Figure 4. Images of calcium deposition in differentiating MC3T3-E1 cells. Cells were grown in osteogenic medium for 21 days, in the presence of NSAIDs $\left(10^{-6} \mathrm{M}\right)$ or prednisolone $\left(10^{-6} \mathrm{M}\right)$ or in the absence of drugs (control). Optical microscopy images depict cells after Alizarin Red S staining, where calcium deposition can be observed within the cell matrix (arrow). NSAIDs, non-steroidal anti-inflammatory drugs.

MC3T3-E1 cells. To this end we treated MC3T3-E1 cells with NSAIDs at $10^{-6} \mathrm{M}$ and $10^{-5} \mathrm{M}$ and assessed cell viability after 5,10 and 15 days of treatment. Regardless of concentration, all NSAIDs significantly decreased the cell viability compared to untreated cells, with the exception of paracetamol at $10^{-6} \mathrm{M}$ (Fig. 1).

NSAIDs alter ALP activity. Next, we examined the effect of NSAIDs on the osteogenic capacity of MC3T3-E1 cells. We first tested their effect on ALP activity under osteogenic culture conditions. With time, ALP activity increased in cells cultured under osteogenic conditions (control). Addition of the non-selective COX inhibitors lornoxicam and diclofenac as well as the selective COX-2 inhibitor meloxicam during differentiation, reduced ALP activity. Parecoxib and paracetamol did not affect ALP activity. In stark contrast, treatment of cells with prednisolone strongly increased ALP activity (Fig. 2).

NSAIDs alter calcium deposition. Along the same line, we examined how calcium deposition is altered by NSAIDs in pre-osteoblasts. Therefore, we cultured MC3T3-E1 cells for 21 days in the presence or absence of drugs and performed 
Table I. Summary of the effect of NSAIDs $\left(10^{-6} \mathrm{M}\right)$ and prednisolone $\left(10^{-6} \mathrm{M}\right)$ in MC3T3-E1 cells.

\begin{tabular}{lccc}
\hline $\begin{array}{l}\text { Drug treatment } \\
\left(10^{-6} \mathrm{M}\right)\end{array}$ & $\begin{array}{c}\text { Cell } \\
\text { viability }\end{array}$ & $\begin{array}{c}\text { ALP activity } \\
\text { (Day 7) }\end{array}$ & $\begin{array}{l}\text { Calcium } \\
\text { Deposits } \\
\text { (Day 21) }\end{array}$ \\
\hline $\begin{array}{l}\text { Lornoxicam } \\
\text { Parecoxib }\end{array}$ & $\begin{array}{l}\text { Decreased } \\
\text { Decreased }\end{array}$ & $\begin{array}{l}\text { Decreased } \\
\text { No change }\end{array}$ & $\begin{array}{l}\text { Increased } \\
\text { Increased }\end{array}$ \\
$\begin{array}{l}\text { Meloxicam } \\
\text { Diclofenac }\end{array}$ & $\begin{array}{l}\text { Decreased } \\
\text { Decreased }\end{array}$ & $\begin{array}{l}\text { Decreased } \\
\text { Decreased }\end{array}$ & $\begin{array}{l}\text { Increased } \\
\text { Increased }\end{array}$ \\
$\begin{array}{l}\text { Pracetamol } \\
\text { Prednisolone }\end{array}$ & No change & No change & Increased \\
(steroid) & & Increased & Decreased \\
\hline
\end{tabular}

NSAIDs, non-steroidal anti-inflammatory drugs; ALP, alkaline phosphatase.

ARS staining. Extraction and quantitative analysis of the deposits revealed that all NSAIDs increased calcium deposition (Figs. 3 and 4) in contrast to prednisolone, which significantly reduced the amount of calcium in the extracellular matrix. Table I summarizes the results on the effects of the tested NSAIDs on cell viability and osteogenic differentiation potential.

\section{Discussion}

In the current study, we investigated the in vitro effects of various non-selective or selective COX-2 inhibitor NSAIDs as well as prednisolone on the viability and osteogenic differentiation of osteoblast precursor cells. Currently, there is little evidence on the effects of NSAIDs specifically on MC3T3-E1 cells. To our knowledge, our study is the first to simultaneously investigate five different NSAIDs for their effects on this cell line. Regarding cellular viability, we found the effects of NSAIDs on mouse pre-osteoblasts to be dose and in certain conditions (meloxicam and paracetamol at $10^{-5} \mathrm{M}$ ), time dependent. All NSAIDs suppressed the proliferation of MC3T3-E1 cells at the concentrations tested, except paracetamol at $10^{-6} \mathrm{M}$, which had no effect. The dose-dependent effect was more evident for lornoxicam, diclofenac and meloxicam. Our findings are in agreement with previous studies which showed that both non-selective and selective COX-2 inhibitor NSAIDs inhibited the growth of osteoblasts: The cell number of cultured human osteoblasts was reported to decrease following treatment with indomethacin for 5 days (35) and in another study, MC3T3-E1 cells treated with indomethacin $(0.1 \mu \mathrm{M})$ and celecoxib (1.5, 3.0, and $9.0 \mu \mathrm{M})$ displayed slower growth than the control group (36). Both studies reported that when more than one drug concentrations were tested, the inhibitory effect was dose-dependent. However, our group has previously demonstrated that at $10^{-6} \mathrm{M}$, NSAIDs enhanced the viability of human adipose derived stem cells (hADSC). At $10^{-5} \mathrm{M}$, only the non-selective COX-2 inhibitors displayed cell growth-suppressive effects on hADSC (22). Our current study suggests that the specific effects of NSAIDs greatly depend on the cell type and species, in addition to dose and time of treatment and in agreement with other reports $(37,38)$. Secondly, regarding the effects on osteogenic differentiation, we found that NSAIDs do not alter the ALP activity of mouse MC3T3-E1 cells, with the exception of lornoxicam, meloxicam and diclofenac $\left(10^{-6} \mathrm{M}\right)$, which reduce ALP activity only after 7 days of treatment. Our results also show, that the mineralization ability of mouse pre-osteoblasts determined as calcium deposits, is enhanced by all NSAIDs at $10^{-6} \mathrm{M}$. For lornoxicam, meloxicam and diclofenac, this finding does not correlate well to the small inhibitory effect exerted on ALP activity (Fig. 2), as an increase in both ALP and calcium deposits are considered markers of osteogenic differentiation. However, previous studies on different cell types demonstrated that calcium deposition or ALP may not be influenced by NSAIDs $(10,35,39)$. For example, diclofenac was reported to have no effect on the mineralization of mouse BMSCs and human MSCs $(10,39)$. We have previously reported, that meloxicam and paracetamol enhanced the mineralization of hADSC, while lornoxicam, diclofenac and parecoxib, had no effect (22).

Paracetamol was also investigated in this study; it is not a typical NSAID, but it appears to inhibit COX-2 to a degree similar to that of selective COX2 inhibitors and other NSAIDs (40). However, the underlying mechanism is believed to be more complex with several factors involved, including inhibition of PG synthesis, induction of apoptosis by different pathways and cell cycle arrest $(41,42)$. In this study, we did not observe any significant reduction in the proliferation capacity (except for $10^{-5} \mathrm{M}$ and 15 -day treatment) or osteogenic maturation of the paracetamol-treated MC3T3-E1 cells at $10^{-6} \mathrm{M}$. A previous study has reported inhibition of ALP activity of MC3T3-E1 but a higher doses of paracetamol (33-330 $\mu \mathrm{M})$ (43).

The effect of prednisolone on MC3T3-E1 cells was found to differ from that of NSAIDs in this study: The steroid drug had a comparable effect to that of NSAIDs' on the viability of growing cultures of MC3T3 pre-osteoblasts, but markedly increased the ALP activity in confluent cultures undergoing osteogenic differentiation. Simultaneously, prednisolone reduced calcium deposition. We found that prednisolone $\left(10^{-6} \mathrm{M}\right)$ induced a stimulatory effect on the ALP activity of MC3T3-E1 cells when normalized to live cells. Notably, over the course of the experiments in osteogenic media, we observed that prednisolone $\left(10^{-6} \mathrm{M}\right)$ dramatically reduced the viability of confluent differentiating cells (to about $50 \%$ as compared to the control group-data not shown). This suggests that prednisolone may initiate apoptosis of confluent osteoblast cultures, leading to fewer osteoblasts in the culture. In fact, the negative effects of corticosteroids on bone physiology are well established and corticosteroid treatment is accepted as a cause of drug-induced (secondary) osteoporosis (44). Previous studies have shown that glucocorticoids act directly on osteoblasts and osteocytes and induce apoptosis, but are also essential in the regulation of osteoblast differentiation (45). However, reported data have shown different or even contradictive outcomes on whether glucocorticoids inhibit or increase biological activity of skeletal cells, including osteoblasts, osteoclasts, osteocytes and their precursors. Their activities on osteoblasts depend on concentration, different developing stages of osteoblasts or osteoblast precursors, different species and kinds of glucocorticoids (46). 
Future studies concerning changes in the osteogenic marker gene expression as well as the antigenic profile of the pre-osteoblastic cells will provide more insight into the mechanism of the action of NSAIDs on these cells. Some gene expression studies have already been conducted on human osteoblasts and the osteosarcoma osteoblast-like cell line MG63 (42). Regarding MC3T3-E1, Nagano et al found that celecoxib inhibited the mRNA expression of both Runx2 and Alp (47). While further investigation is needed, we currently have preliminary data (Data S1) to suggest that none of the NSAIDs investigated in this study inhibits the gene expression of either Runx2 or Bsp genes (Fig. S1).

In conclusion, the present in vitro study examined the interference of NSAIDs and prednisolone with the proliferation and the osteogenic differentiation of mouse pre-osteoblasts, a process that directly affects osteoblast physiology and ultimately bone healing. Through the present study as well as our previous study on ADMSCs, we have shown that NSAIDs can modulate the behaviour of osteoblasts but not all NSAIDs share specific effects, in agreement with previous reports (11). Certainly, prednisolone, a synthetic glucocorticoid appears as the outlier in the osteogenic differentiation experiments we performed. Its behaviour does not correlate well to that of the NSAID group nor does its structure as a steroid lipid molecule belonging to the class of organic compounds known as 21-hydroxysteroids. It has been reported that high glucocorticoid levels therapies impair bone growth leading to glucocorticoid-induced osteoporosis (48). Elucidating structure-activity relationships for NSAIDs requires data sets that provide experimental measurements of activity for a group of chemicals defined by some selection criteria in terms of structure. A statistical analysis method can then be applied to relate structure to activity. A recent review study on quantitative structure activity relationships (QSAR) of NSAIDs has identified a link between functional groups which enhance the lipophilicity and an increase in the anti-inflammatory activity of the drugs (49). Structural characteristics of the NSAIDs have been reported to govern anti-inflammatory activity, including steric factors, physicochemical parameters expressing the overall volume/size of the molecules, molar refractivity, the role of heteroatoms such as nitrogen or sulfur in the heteroatomic system bearing one or two phenyl rings and at least one carbonyl group, and finally electronic parameters, indicative of dipole-dipole or charge-dipole interactions, charge-transfer phenomena and hydrogen bond formation (50). It would be certainly helpful to explore derivatives with a wider spread in substituents to study the effect of these physicochemical structural features. Overall, it can be stated that there is a similarity in terms of the requirement for hydrophobicity and size of the molecules for both COX-1 and COX-2 receptors (50). In the same direction, data sets from our study as well as similar studies on NSAIDs are important for modelling NSAID structure-activity relations in relation to their effects on osteogenic response and cell proliferation. Even though concrete conclusions on structure-activity cannot be drawn from a single study, these data may be useful in future QSAR studies of NSAIDs $(49,50)$. Given the potential clinical implications, our findings are also expected to be beneficial to further investigation through in vivo studies.

\section{Acknowledgements}

The authors would like to thank Dr Vasileia Ismini Alexaki (Institute of Clinical Chemistry and Laboratory Medicine, Faculty of Medicine and University Clinic Carl Gustav Carus, Technische Universität Dresden, Germany) for aiding in useful discussion regarding this manuscript.

\section{Funding}

No funding was received.

\section{Availability of data and materials}

The datasets used and/or analyzed during the current study are available from the corresponding author on reasonable request.

\section{Authors' contributions}

$\mathrm{CH}, \mathrm{KA}$ and $\mathrm{MC}$ made substantial contributions to conception and design of the study and the experiments, $\mathrm{CH}$ performed the experiments, analyzed and interpreted the data, $\mathrm{CH}$ and $\mathrm{KA}$ wrote the manuscript, $\mathrm{MC}$ revised the manuscript. All authors read and approved the final manuscript.

\section{Ethics approval and consent to participate}

Not applicable.

\section{Patient consent for publication}

Not applicable.

\section{Competing interests}

The authors declare that they have no competing interests.

\section{References}

1. Barry S: Non-steroidal anti-inflammatory drugs inhibit bone healing: A review. Vet Comp Orthop Traumatol 23: 385-392, 2010.

2. Cottrell $\mathrm{J}$ and O'Connor JP: Effect of non-steroidal anti-inflammatory drugs on bone healing. Pharmaceuticals (Basel) 3: 1668-1693, 2010.

3. Pountos I, Georgouli T, Blokhuis TJ, Pape HC and Giannoudis PV: Pharmacological agents and impairment of fracture healing: What is the evidence? Injury 39: 384-394, 2008.

4. Patschan D, Loddenkemper K and Buttgereit F: Molecular mechanisms of glucocorticoid-induced osteoporosis. Bone 29: 498-505, 2001.

5. Canalis E: Mechanisms of glucocorticoid action in bone. Curr Osteoporos Rep 3: 98-102, 2005.

6. O'Brien CA, Jia D, Plotkin LI, Bellido T, Powers CC, Stewart SA, Manolagas SC and Weinstein RS: Glucocorticoids act directly on osteoblasts and osteocytes to induce their apoptosis and reduce bone formation and strength. Endocrinology 145: 1835-1841, 2004.

7. Paget S: Steroids cause osteoporosis. Ann Rheum Dis 61: 1-3, 2002.

8. Harder AT and An YH: The mechanisms of the inhibitory effects of nonsteroidal anti-inflammatory drugs on bone healing: A concise review. J Clin Pharmacol 43: 807-815, 2003. 
9. Pountos I, Georgouli T, Calori GM and Giannoudis PV: Do nonsteroidal anti-inflammatory drugs affect bone healing? A critical analysis. ScientificWorldJournal 2012: 606404, 2012.

10. Chang JK, Li CJ, Wu SC, Yeh CH, Chen CH, Fu YC, Wang GJ and Ho ML: Effects of anti-inflammatory drugs on proliferation, cytotoxicity and osteogenesis in bone marrow mesenchymal stem cells. Biochem Pharmacol 74: 1371-1382, 2007.

11. García-Martínez O, De Luna-Bertos E, Ramos-Torrecillas J, Manzano-Moreno FJ and Ruiz C: Repercussions of NSAIDS drugs on bone tissue: The osteoblast. Life Sci 123: 72-77, 2015.

12. Díaz-Rodríguez L, García-Martínez O, De Luna-Bertos E, Ramos-Torrecillas J and Ruiz C: Effect of ibuprofen on proliferation, differentiation, antigenic expression, and phagocytic capacity of osteoblasts. J Bone Miner Metab 30: 554-560, 2012.

13. De Luna-Bertos E, Ramos-Torrecillas J, García-Martínez O, Guildford A, Santin M and Ruiz C: Therapeutic doses of nonsteroidal anti-inflammatory drugs inhibit osteosarcoma MG-63 osteoblast-like cells maturation, viability, and biomineralization potential. ScientificWorldJournal 2013: 809891, 2013

14. Costela-Ruiz VJ, Melguizo-Rodríguez L, Illescas-Montes R, Ramos-Torrecillas J, Manzano-Moreno FJ, Ruiz C and Bertos EL: Effects of therapeutic doses of celecoxib on several physiological parameters of cultured human osteoblasts. Int J Med Sci 16: 1466-1472, 2019.

15. Wheatley BM, Nappo KE, Christensen DL, Holman AM, Brooks DI and Potter BK: Effect of NSAIDs on bone healing rates: A meta-analysis. J Am Acad Orthop Surg 27: e330-e336, 2019.

16. Lisowska B, Kosson D and Domaracka K: Positives and negatives of nonsteroidal anti-inflammatory drugs in bone healing The effects of these drugs on bone repair. Drug Des Devel Ther 12: 1809-1814, 2018

17. Geusens P, Emans PJ, de Jong JJ and van den Bergh J: NSAIDs and fracture healing. Curr Opin Rheumatol 25: 524-531, 2013.

18. Beck A, Salem K, Krischak G, Kinzl L, Bischoff M and Schmelz A: Nonsteroidal anti-inflammatory drugs (NSAIDs) in the perioperative phase in traumatology and orthopedics effects on bone healing. Oper Orthop Traumatol 17: 569-578, 2005 (In English, German).

19. Gerstenfeld LC, Thiede M, Seibert K Mielke C, Phippard D, Svagr B, Cullinane D and Einhorn TA: Differential inhibition of fracture healing by non-selective and cyclooxygenase- 2 selective non-steroidal anti-inflammatory drugs. J Orthop Res 21: 670-675, 2003.

20. Herbenick MA, Sprott D, Stills H and Lawless M: Effects of a cyclooxygenase 2 inhibitor on fracture healing in a rat model Am J Orthop (Belle Mead NJ) 37: E133-E137, 2008

21. Manzano-Moreno FJ, Costela-Ruiz VJ, Melguizo-Rodriguez L, Illescas-Montes R, García-Martínez O, Ruiz C and Ramos-Torrecillas J: Inhibition of VEGF gene expression in osteoblast cells by different NSAIDs. Arch Oral Biol 92: 75-78, 2018.

22. Hadjicharalambous C, Alexaki VI, Alpantaki K and Chatzinikolaidou M: Effects of NSAIDs on the osteogenic differentiation of human adipose tissue-derived stromal cells J Pharm Pharmacol 68: 1403-1408, 2016.

23. Jain NX, Barr-Gillespie AE, Clark BD, Kietrys DM, Wade CK, Litvin J, Popoff SN and Barbe MF: Bone loss from high repetitive high force loading is prevented by ibuprofen treatment J Musculoskelet Neuronal Interact 14: 78-94, 2014

24. Darnis D, Veyrac G and Jolliet P: The special case of diclofenac. Enliven: Pharmacovigil Drug Saf 1: 3, 2014.

25. Schwarting T, Pretzsch S, Debus F, Ruchholtz S and Lechler P: The effect of cyclooxygenase inhibition on tendon-bone healing in an in vitro coculture model. Med Inflammation 2015: 926369, 2015.

26. Kidd LJ, Cowling NR, Wu AC, Kelly WL and Forwood MR Selective and non-selective cyclooxygenase inhibitors delay stress fracture healing in the rat ulna. J Orthop Res 31: 235-242, 2013.

27. Vuolteenaho K, Moilanen T and Moilanen E: Non-steroida anti-inflammatory drugs, cyclooxygenase- 2 and the bone healing process. Basic Clin Pharmacol Toxicol 102: 10-14, 2008.

28. Marquez-Lara A, Hutchinson ID, Nunez F Jr, Smith TL and Miller AN: Nonsteroidal anti-inflammatory drugs and bone-healing: A systematic review of research quality. JBJS Rev 4: 01874474-201603000-00005, 2016.

29. Graham GG, Davies MJ, Day RO, Mohamudally A and Scott KF: The modern pharmacology of paracetamol: Therapeutic actions, mechanism of action, metabolism, toxicity and recent pharmacological findings. Inflammopharmacology 21: 201-232, 2013.

30. Kodama H, Amagai Y, Sudo H and Yamamoto S: Establishment of a clonal osteogenic cell line from newborn mouse calvaria. Jpn J Oral Biol 23: 899-901, 1981.
31. Golub E and Boesze-Battaglia KJ: The role of alkaline phosphatase in mineralization. Curr Opin Orthopaedics 18: 444-448, 2007.

32. Hadjicharalambous C, Buyakov A, Buyakova S, Kulkov S and Chatzinikolaidou M: Porous alumina, zirconia and alumina/ zirconia for bone repair: fabrication, mechanical and in vitro biological response. Biomed Mater 10: 025012, 2015.

33. Feng Y, Su L, Zhong X, Guohong W, Xiao H, Li Y and Xiu L: Exendin-4 promotes proliferation and differentiation of MC3T3-E1 osteoblasts by MAPKs activation. J Mol Endocrinol 56: 189-199, 2016.

34. Hadjicharalambous C, Kozlova D, Sokolova V, Epple M and Chatzinikolaidou M: Calcium phosphate nanoparticles carrying BMP-7 plasmid DNA induce an osteogenic response in MC3T3-E1 pre-osteoblasts. J Biomed Mater Res A 103: 38343842,2015

35. Evans CE and Butcher C: The influence on human osteoblasts in vitro of non-steroidal anti-inflammatory drugs which act on different cyclooxygenase enzymes. J Bone Joint Surg Br 86: 444-449, 2004

36. Arpornmaeklong $\mathrm{P}$, Akarawatcharangura $\mathrm{B}$ and Pripatnanont $\mathrm{P}$ : Factors influencing effects of specific COX-2 inhibitor NSAIDs on growth and differentiation of mouse osteoblasts on titanium surfaces. Int J Oral Maxillofac Implants 23: 1071-1081, 2008.

37. Gunaydin $C$ and Bilge SS: Effects of nonsteroidal anti-inflammatory drugs at the molecular level. Eurasian J Med 50: 116-121, 2018.

38. Kotake S, Yago T, Kawamoto $M$ and Nanke Y: Effects of NSAIDs on differentiation and function of human and murine osteoclasts-crucial 'Human osteoclastology'. Pharmaceuticals (Basel) 3: 1394-1410, 2010.

39. Pountos I, Giannoudis PV, Jones E, English A, Churchman S, Field S, Ponchel F, Bird H, Emery P and McGonagle D: NSAIDS inhibit in vitro MSC chondrogenesis but not osteogenesis: Implications for mechanism of bone formation inhibition in man. J Cell Mol Med 15: 525-534, 2011.

40. Hinz B, Cheremina O and Brune K: Acetaminophen (paracetamol) is a selective cyclooxygenase-2 inhibitor in man. FASEB J 22: 383-390, 2008.

41. Díaz-Rodríguez L, García-Martínez O, Arroyo-Morales M, Rubio-Ruiz B and Ruiz C: Effect of acetaminophen (paracetamol) on human osteosarcoma cell line MG63. Acta Pharmacol Sin 31: 1495-1499, 2010.

42. Melguizo-Rodriguez L, Costela-Ruiz VJ, Manzano-Moreno FJ, Illescas-Montes R, Ramos-Torrecillas J, García-Martínez O and Ruiz C: Repercussion of nonsteroidal anti-inflammatory drugs on the gene expression of human osteoblasts. PeerJ 6: e5415, 2018.

43. Nakatsu Y, Nakagawa F, Higashi S, Ohsumi T, Shiiba S, Watanabe $\mathrm{S}$ and Takeuchi $\mathrm{H}$ : Effect of acetaminophen on osteoblastic differentiation and migration of MC3T3-E1 cells. Pharmacol Rep 70: 29-36, 2018.

44. Sivagurunathan S, Muir MM, Brennan TC, Seale JP and Mason RS: Influence of glucocorticoids on human osteoclast generation and activity. J Bone Miner Res 20: 390-398, 2005.

45. Mitra R: Adverse effects of corticosteroids on bone metabolism: A review. PM R 3: 466-471, 2011.

46. Hong D, Chen HX, Ge RS and Li JC: The biological roles of extracellular and intracytoplasmic glucocorticoids in skeletal cells. J Steroid Biochem Mol Biol 111: 164-170, 2008.

47. Nagano A, Arioka M, Takahashi-Yanaga F, Matsuzaki E and Sasaguri T: Celecoxib inhibits osteoblast maturation by suppressing the expression of Wnt target genes. J Pharmacol Sci 133: 18-24, 2017.

48. Hachemi Y, Rapp AE, Picke AK, Weidinger G, Ignatius A and Tuckermann J: Molecular mechanisms of glucocorticoids on skeleton and bone regeneration after fracture. J Mol Endocrinol 61: R75-R90, 2018

49. Asirvatham S, Dhokchawle BV and Tauro SJ: Quantitative structure activity relationships studies of non-steroidal anti-inflammatory drugs: A review. Arabian J Chem 12: 3948-3962, 2019

50. Michaelidou AS and Hadjipavlou-Litina D: Nonsteroidal anti-inflammatory drugs (NSAIDs): A comparative QSAR study. Chem Rev 105: 3235-3271, 2005. 